\title{
Gestión de una comunicación escrita eficaz del tutor virtual durante los procesos de enseñanza aprendizaje en los cursos en línea en la UNED
}

\section{Francisco Mora Vicarioli}

Productor académico del Programa de Aprendizaje en Línea. Universidad Estatal a Distancia.fmora@uned.ac.cr

Recibido: 12 de marzo del 2014

\section{RESUMEN}

Este artículo presenta los resultados de la investigación realizada sobre comunicación para cursos en línea, para el Trabajo Final de Graduación de la Maestría en Tecnología de la UNED, la cual tenía entre sus propósitos crear un producto multimedial sobre esta temática, como apoyo para los procesos comunicativos que se desarrollan en los cursos en línea. Las diferentes herramientas de los cursos en línea permiten una comunicación tanto asincrónica (no simultánea) como sincrónica (simultánea), además que se le facilita al docente ofrecer una realimentación más rápida y oportuna con el estudiantado, esto es un cambio de paradigma en la educación a distancia a la cual se debe enfrentar el profesorado. Es por este motivo que el rol del tutor a distancia cambia y requiere nuevas competencias para el manejo de este tipo de entornos virtuales de aprendizaje.

\section{PALABRAS CLAVE}

Cursos en línea, tutor virtual, educación a distancia, plataformas de aprendizaje en línea y comunicación.
Aceptado: 24 de abril del 2014

\begin{abstract}
SUMMARY
This article presents the results of the research on communication for online courses for the Final Graduation of Master of Technology UNED, which had among its create a multimedia product on this subject, as support for process purposes communication taking place in online courses. Different tools online courses allow both asynchronous (not simultaneous) and synchronous (simultaneous) communication that is provided in addition to teachers provide a more rapid and timely feedback to students, this is a paradigm shift in education distance to which teachers must face. It is for this reason that the role of tutor to distance changes and requires new skills for handling this kind of virtual learning environments
\end{abstract}

\section{KEY WORDS}

Online courses, virtual tutor, distance education, online learning platforms and communication.

\section{INTRODUCCIÓN}

La enseñanza a distancia se encuentra actualmente apoyada por el uso de las tecnologías, las plataformas de aprendizaje en línea proporcionan una serie de recursos que permiten variar las dinámicas tradicionales de la educación a distancia (como la tutoría epistolar).

La comunicación en cursos en línea es vital para desarrollar procesos educativos de la manera adecuada, el estudiante a distancia espera la presencia de su tutor y que este le brinde orientación 
durante todo el proceso. Particularmente, se hace indispensable en cursos que tienen un uso intensivo del recurso virtual, es decir, el espacio donde se realizan la mayoría de las actividades evaluativas.

Las actividades en los cursos en línea requieren una comunicación clara por parte del tutor, lo que no siempre resulta sencillo y cambia dada la variedad de herramientas que las plataformas ofrecen y las posibilidades de interacción que permiten; por ello; resulta muy importante que el tutor comunique claramente lo que desea que realicen los estudiantes, a fin de no entorpecer los procesos educativos.

El desarrollo de una comunicación efectiva, aunado al correcto uso de tales entornos, es posible con apoyo de la Universidad Estatal a Distancia (UNED) de Costa Rica por medio de capacitación y asesoría en cuanto a su adecuada implementación.

La mayoría del profesorado a cargo de los cursos en línea fue formado en el contexto de la educación tradicional (presencial). Por lo tanto, no existe una idea clara de la forma en que se desarrolla un proceso educativo mediante las plataformas de aprendizaje en línea; así mismo, la incursión en dichos entornos desde el rol del facilitador, requiere experiencia y capacitación a causa de la diferencia que existe con la modalidad de la enseñanza presencial; entonces, la institución cuenta con instancias que apoyan los procesos de virtualización.

Si bien, la institución cuenta con unidades o instancias de capacitación y asesoría, es importante contar con medios alternos para orientar al profesorado respecto del modo de llevar a cabo la comunicación escrita en los entornos virtuales de aprendizaje.

Los tutores en línea de la UNED muchas veces no inician sus labores con la capacitación o experiencia necesaria para lograr desempeñarse adecuadamente en un curso en la modalidad virtual. Tal situación justifica la relevancia de contar con medios e insumos para orientar al personal que cumple tales labores académicas.

\section{- Antecedentes y justificación}

La comunicación en los cursos en línea requiere una mayor precisión puesto que tiene que ver con el acompañamiento que brinda el tutor virtual durante el proceso de enseñanza aprendizaje. La administración adecuada de dicho elemento en un curso en línea implica necesariamente una serie de pautas para su ejecución y para una correcta realimentación entre los involucrados.

El estudio de la comunicación escrita se enfocó en proporcionar una serie de pautas para propiciar la mejora de la comunicación mediante una adecuada administración de esta, que permite a la vez una mediación más eficaz en los cursos en línea. Se pretende, por ello, identificar las funciones del profesorado en lo que a la adecuada expresión escrita se refiere, específicamente en los entornos virtuales, propiamente en la mediación que esta puede brindar en esos ambientes educativos.

La UNED, gracias al Centro de Capacitación en Educación a Distancia (CECED), brinda una variada oferta de capacitación para los funcionarios. De esos cursos, el de Pedagogía Universitaria en la Educación a Distancia y el de Diseño y Organización de Cursos en Línea son obligatorios para trabajar como docente de cursos en línea. Ambos cursos orientan a propósito de la metodología de la UNED, el modelo pedagógico, las características del público meta (perfil estudiantil) y el uso óptimo de los entornos virtuales de aprendizaje en lo tecnológico y lo pedagógico. Existen algunos otros cursos que brinda esta instancia y que son complementarios a los mencionados, tendentes a mejorar las competencias de los tutores en la evaluación de los aprendizajes y tutoría virtual.

En algunas ocasiones y a causa de las necesidades urgentes de profesorado para laborar en los diferentes cursos en línea, éstos inician sus 
labores sin contar con la capacitación prevista, o bien se va cursando de manera paralela.

El Área de Comunicación y Tecnología de la Dirección de Extensión Universitaria (Dirextu) de la UNED trata de orientar a su profesorado en cuanto al aprovechamiento adecuado de los entornos virtuales: durante las reuniones de personal y por medio de talleres cortos presenciales y virtuales, se trabaja para propiciar el correcto uso de herramientas de comunicación y la evaluación correcta de los cursos en línea como parte de los esfuerzos para mejorar la gestión académica de los entornos en línea.

Casi la totalidad del profesorado del Área de Comunicación y Tecnología labora en jornadas de medio tiempo y de cuarto de tiempo para la institución pues tienen su tiempo completo en otras entidades. Es, pues, un inconveniente en cuanto a la disponibilidad para que el personal reciba la capacitación necesaria.

Es importante anotar que en esta área no se han realizado aún investigaciones acerca de la temática de la tutoría virtual o comunicación en los cursos en línea que se imparten. Entonces, es cuestionamiento que se debe indagar para conocer mejor la forma en que se realiza.

De manera adicional, el Área ha contado con personal a cargo del monitoreo de los cursos, con el fin de detectar posibles mejoras en el nivel de materiales, la atención en los espacios de comunicación y apertura de actividades y la distribución de semanas o módulos de trabajo.

\section{MARCO TEÓRICO}

\section{- Institución}

La UNED ofrece gran cobertura física en el país con sus más de 35 centros universitarios, los cuales permiten desarrollar tutorías presenciales, ofrecen apoyo administrativo y académico pues proporcionan al estudiantado, en algunos casos, acceso a laboratorios de cómputo con conexión a internet.
La institución va más allá de la cobertura física, ya que se orienta hacia la educación a distancia apoyada por plataformas virtuales de aprendizaje. Actualmente, se cuenta con varias asignaturas que se imparten con apoyo de ese recurso. Por ejemplo, en el 2010 se reportaron 771 cursos virtuales; en el 2011, ya se contaba con 932 y en el 2012 se ofertaron 1062, según estadísticas del Programa de Aprendizaje en Línea (PAL), instancia encargada de la administración de la matrícula y apertura de cursos virtuales dirigidos a los estudiantes de la UNED.

\section{- La comunicación y su importancia}

En el proceso de comunicación están implicados varios elementos: emisor, receptor, mensaje, canal y contexto. Señalan Roldán y otros (2012) en relación con algunos de esos elementos: se relacionan entre sí a través de operaciones (emisión, transmisión y recepción) que se distinguen en niveles: psíquico, físico y fisiológico, integrados dentro de un proceso que corresponde a un tipo social de relación, en el que se ha establecido un código definido y común: el idioma o lengua.

El canal es relativo al medio por el cual se envía el mensaje, en cuanto al contexto, este es clasificado de manera distinta, pero destacan el contexto de tipo idiomático y cultural, dada su aplicabilidad en los procesos comunicativos, esto es señalado por Santos (2012). El estudio idiomático explica como el contexto de las palabras y su relación crean los diferentes significados. El contexto cultural se puede entender de manera sencilla como en diferentes lugares una palabra puede denotar distintos significados.

La comunicación y sus procesos se vuelven efectivos cuando tenemos una serie de procesos como: origen de la idea y su desarrollo, codificación del mensaje, transmisión, recepción, interpretación, aceptación o rechazo, uso del mensaje recibido y reacción por parte del receptor y finalmente la retroalimentación. (Roldán, 2012) 
La comunicación se vuelve adecuada cuando el receptor puede interpretar el mensaje como se requería, lo cual es clave en educación y particularmente en los medios digitales, dadas las características asincrónicas en las que se desarrolla, por ejemplo, en foros de discusión, mensajes de correo electrónico y blogs entre otros.

La intencionalidad de la comunicación es un componente de gran importancia, la intención modela el discurso del emisor, puesto que sus actos lingüísticos irán encaminados a lograr el propósito que persigue (aunque sea de forma inconsciente), a la vez que también influye en la interpretación del receptor.

De lo anterior, se destaca que la intencionalidad influye en la forma en que nos expresamos, esta consideración es clave en el ámbito educativo, particularmente en los medios digitales, donde prevalece la comunicación escrita, la cual requiere de gran precisión para poder transmitir los mensajes que se desean.

- La comunicación escrita en medios digitales

La conformación de la comunicación escrita se divide en tres elementos, mencionados por $\mathrm{Pa}$ zos (2010):

»El fondo o contenido que constituye la esencia del texto: los pensamientos o ideas.

»La forma o vehículo, conformado por oraciones que construyen los elementos.

》)

El estilo que constituye el modo particular como se trata un asunto, dependiendo de la intención del emisor.

Lo señalado es relevante en la generalidad de los medios en que se puede desarrollar una comunicación y cobra más importancia actualmente en los medios digitales.

Según señala Chan (2010) que los medios digitales han cambiado la forma de comunicación entre el profesorado y los estudiantes, se destaca el cambio histórico que se ha dado:

En los 9o, el tipo de experiencia educativa con uso de Internet estuvo ligada al uso de herramientas de organización e intercambio de información. Las herramientas para producir imágenes, escenarios virtuales y manipular cualquier contenido audiovisual, se han generado y difundido en los últimos cinco años de manera vertiginosa, y han colocado a los usuarios de internet en la posibilidad de producir contenido, y no solo de buscar, seleccionar y compartir información. (p. 3-4)

La comunicación escrita en los medios digitales dista de otros tipos de comunicación como la verbal. Cuando se redacta para transmitir un determinado mensaje, si el texto carece de precisión y resulta ambiguo, puede ser interpretado de diferentes maneras.

El uso de la tecnología interviene en los procesos de comunicación, en ese sentido, García (2009) comenta que la formación ha podido acceder a nuevos canales de comunicación que posibilitan el acceso a la información y la transferencia de conocimientos en parámetros antes impensables.

Acerca de la forma en que puede afectar la comunicación en el aprendizaje, Olivier y Shaw (2008), citados por Willing (2008), apuntan que como con cualquier otra tecnología, la Internet y otras herramientas de comunicación tienen limitaciones y crean consecuencias no anticipadas, además la carencia de las señales de la comunicación tradicional en la clase en línea puede ser un impedimento para el aprendizaje. Diferencias en el estilo de conversación pueden afectar el modo en que los estudiantes interactúan, reflexionan y aprenden en el aula virtual.

En un medio digital, normalmente no es posible percibir la reacción del receptor a un mensaje de manera inmediata. La información puede causar diferentes efectos sin que nos demos cuenta oportunamente. En el ámbito educativo, es necesario contar con una comunicación 
escrita eficaz para que existan procesos de enseñanza aprendizaje efectivos, particularmente, en el ambiente de la virtualidad el profesorado se comunica, da instrucciones, guía procesos de discusión e interacción y realimenta; por lo tanto, tales mensajes deben ser adecuados a la audiencia meta para surtir el efecto que buscan.

\section{- La educación a distancia}

El origen de la educación a distancia se remonta al siglo pasado, a pesar de las resistencias sociales, la demanda de este tipo de educación hizo que fuera incorporándose tímidamente, hasta que terminó por imponerse en determinados sectores de la población, especialmente en el campo universitario, señala García (2009).

La educación a distancia se perfila como un modelo educativo pertinente para las necesidades actuales de la sociedad, sus aportes van influyendo a las instituciones presenciales, dado que el uso de las tecnologías se presenta como un apoyo a los procesos de aprendizaje. A propósito, García (2009) señala que la educación a distancia debe tener lugar en escenarios pedagógicos no presenciales, de interacción mediada por tecnologías y con el propósito de garantizar la calidad de la enseñanza.

Los sistemas de educación a distancia presentan una serie de características y rasgos según Pagano (2008):

»Separación profesor-alumno

»Utilización de medios técnicos

》)

Aprendizaje independiente y flexible

Comunicación bidireccional

Enfoque tecnológico

Comunicación masiva
Otra particularidad de la educación a distancia es la mencionada por Ulate y Vargas (2012) como un modelo educativo que no exige la presencialidad, es decir, el aprendizaje se logra a pesar que el estudiante y profesor están separados por el espacio y por el tiempo. El tipo de escenarios de aprendizaje son modelados a partir del uso de la tecnología y éstos cambian la función tanto del profesor como de los estudiantes.

\section{- La comunicación en la educación a distancia}

La comunicación en la educación a distancia evoluciona en cuanto al uso de las tecnologías que se utilizan: gracias a los medios impresos, programas de radio o audiovisuales es posible lograr una comunicación con el estudiantado; sin embargo, nunca en la historia había sido ésta tan intensa como la que es posible desarrollar por medio de la virtualidad.

En la educación a distancia suele ocurrir comunicación de tipo unidireccional y bidireccional. Por medio del uso de diferentes medios didácticos ocurre una comunicación unidireccional con el estudiantado, en éstos no se puede obtener realimentación en el avance del estudio independiente. También, se puede contar con una comunicación bidireccional por medio del uso de las plataformas de aprendizaje en línea, ya que se cuenta con diferentes canales que le permiten al estudiante comunicarse con el profesorado y con los compañeros del curso.

Una visión de la comunicación bidireccional a distancia en medios digitales es la de Sánchez, Puerta y Sánchez (2010) cuando señalan que puede entenderse como el proceso de diseño, producción, valoración, interacción, publicación, edición y visibilidad de diversos contenidos, mediante el uso de las TIC; las cuales, aplicadas al periodismo, a la gestión informativa, a la formación en ambientes virtuales de aprendizaje y a la redacción de contenidos educativos exigen el 
reconocimiento de diversas tipologías textuales y maneras renovadas de contar la realidad, difundir el conocimiento e interactuar; es decir, realizar acciones recíprocas con los otros a partir de la escritura, que es precisamente el enfoque central de este manual, como lo mencionan

Con el uso de las plataformas de aprendizaje en línea, es posible contar con una comunicación más fluida por distintos medios como: foros, blogs, correo interno, anuncios, chat y videoconferencia. Se puede desarrollar una comunicación en ambas vías, tanto sincrónica como asincrónica; esta última es la más común en los cursos en línea.

Respecto de la comunicación que se desarrolla en la educación a distancia y particularmente en las plataformas virtuales, Angulo (2013) advierte que se deben establecer reglas claras pues el estudiante puede pensar que el profesorado está conectado y dispuesto para contestar consultas las 24 horas del día; por ello, se debe dejar en claro la naturaleza asincrónica de tales entornos.

Por otra parte, Chan (2010) señala una de las implicaciones de la forma en que se desarrolla la comunicación en los EVA:

Al no ser sincrónica y gestual la comunicación en la educación en línea, depende en muy alto grado de la capacidad expresiva textual, y eso provoca desconcierto y también un buen número de interpretaciones equivocadas, sobre todo en el plano de la afectividad que acompaña la relación educativa.

Los canales de comunicación que se llevan a cabo en las plataformas de aprendizaje en línea son muy variados: instrucciones, anuncios, mensajes personalizados, atención en foros de consultas, mediación de espacios y realimentación o calificación de actividades evaluativas. El tutor en línea crea instrucciones para las actividades; dichas indicaciones son de gran relevancia a fin de orientar la entrega que se desea por parte del estudiante. En la medida en que la instrucción escrita sea lo suficientemente clara, es posible propiciar una mejor entrega de las asignaciones.

Los anuncios o avisos son parte de la comunicación importante que se desarrolla en un curso en línea. El profesorado puede dinamizar y mostrar su presencia durante el periodo del curso; también, puede evitar que los estudiantes olviden eventos significativos como entrega de tareas y participación en foros, por ejemplo.

Los mensajes personalizados por medio del correo interno de las plataformas permiten tratar situaciones particulares con estudiantes, o bien, generar orientación en caso de errores cometidos en las distintas actividades evaluativas o resolver conflictos disciplinarios dentro de los espacios de trabajo grupales. La que se realice debe ser por medio de una comunicación escrita precisa para que sea bien recibida por parte del estudiante.

El foro de consultas o de dudas resulta un espacio de comunicación de uso generalizado en los cursos en línea, por medio de este tipo de foro, el profesor debe aclarar las inquietudes planteadas, toda vez que sus respuestas sean claras y precisas se logra que no solo el consultante pueda orientarse, sino que todo el grupo puede sacar provecho de estas aclaraciones.

La mediación de espacios se refiere a la forma en que el profesorado interviene en dinámicas tanto individuales como grupales, desde la comunicación que desarrolla, el tipo de mensajes que redacta hasta la evaluación que brinda. La mediación en espacios individuales sucede en: blogs, tareas o diarios de curso mediante los cuales el docente realimenta y guía al estudiante, por otra parte, la mediación en actividades grupales ocurren en los foros de discusión o wikis, en los que se participa con la instrucción inicial que desencadena la discusión o trabajo grupal y también se refiere a la manera en que el tutor oriente y dinamice el entorno virtual, esto afectará el provecho de este tipo de espacios, en tales casos, la comunicación escrita del tutor es fundamental para motivar los aportes del grupo. 
En la realimentación o calificación de actividades, se debe tener en cuenta que las dinámicas en línea no deben ser calificadas únicamente con un puntaje: debe estar acompañado de un instrumento evaluador que justifique el puntaje obtenido por el estudiante. Gracias a este tipo de realimentación y comentarios que las plataformas facilitan, el tutor puede orientar de manera formativa las entregas, lo cual se debe realizar por medio de una comunicación escrita que el estudiante reciba adecuadamente.

\section{- El estudiante a distancia y la comunicación}

Antes, en la educación a distancia tradicional, la comunicación no se realizaba directamente con el profesorado, éste solamente brindaba realimentación en las evaluaciones de los cursos (proyectos, tareas, exámenes entre otros); por ende, el acompañamiento para el estudiantado era escaso y la relación con otros compañeros resultaba bastante limitada.

Con el avance de las tecnologías, hoy, la educación a distancia brinda al estudiante una comunicación más fluida: dadas las posibilidades de interacción de las plataformas de aprendizaje en línea, los procesos comunicativos que se realizan son mayoritariamente escritos y asincrónicos, así, es factible un mejor acompañamiento y más realimentación oportuna para el estudiante a distancia, por ello, el uso de los espacios de interacción y comunicación antes descritos son relevantes.

\section{- La tutoría y el tutor virtual}

La tutoría virtual es la que se realiza en el marco de la educación a distancia apoyada por tecnología y el tutor virtual es quien ejerce tal acción. Dicho tipo de entrega de la docencia resulta un nuevo paradigma en la docencia y es fundamental tener presente que la especialización del profesorado hacia la tutoría virtual requiere un gran esfuerzo por parte de la institución en términos de capacitación, orientación, asesoría y soporte técnico, a fin de afrontar los múltiples retos como los comunicativos, de mediación y realimentación.

El tutor virtual hace la entrega de la docencia, ya no de manera presencial, sino por medio de las plataformas de aprendizaje virtual; pero esa docencia es sustancialmente distinta al trabajo que desarrolla el profesorado en la modalidad presencial. La diferencia radica en los medios tecnológicos y en específico los EVA en los que el docente replantea su labor gracias a las posibilidades tecnológicas y los espacios de interacción.

El profesional que se desempeña en el entorno virtual para un proceso de enseñanza aprendizaje, usualmente se denomina tutor virtual. Como se estudiará a continuación, este tipo de profesional presenta una serie de características deseables para su buen desempeño.

\section{- Cualidades del tutor virtual}

El cuerpo docente que se desempeña en el modelo a distancia presenta una serie de retos, pues debe replantear la enseñanza desde la óptica de la modalidad presencial. Pagano (2008) indica un eje importante en esta labor: La primera tarea que debe desarrollar un tutor es lograr confianza en el alumno en cuanto al sistema de educación a distancia, orientándolo en su metodología. Por ello, el tutor debe conocer los fundamentos de la formación a distancia, las funciones que debe cumplir y las estrategias a emplear en la mediación pedagógica.

Entre las cualidades del tutor virtual están las indicadas por Fernández, Mireles y Aguilar (2010): cordialidad, capacidad de aceptación, empatía y escucha activa. Las cuatro se relacionan en gran medida con una adecuada comunicación, propician la cortesía y la cordialidad en el entorno virtual del curso. 
Igualmente, hay armonía cuando el tutor asume una serie de funciones y ostenta las competencias y las cualidades necesarias, sean éstas parte de su bagaje u obtenidas de la capacitación necesaria para desempeñarse en la virtualidad, de esa manera, ayuda a propiciar que los cursos en línea sean exitosos.

El tutor virtual debe ser un profesional de alta organización porque los EVA implican varias funciones como apertura de actividades, revisión y contestación en los espacios de consulta, y búsqueda de materiales.

La capacitación y el autoaprendizaje son claves: el tutor virtual debe estar anuente a actualizarse de manera constante, particularmente en cuanto al uso de las tecnologías y su aprovechamiento en el EVA.

\section{- Mediación de cursos en línea}

La mediación de los cursos en línea es relativa a la función pedagógica que debe cumplir el tutor virtual en el curso. Algunas de las competencias del profesorado deben ser el conocimiento del modelo de educación superior a distancia y específicamente del Modelo Pedagógico de la UNED, el cual brinda orientación respecto del origen de la institución, las características del público meta, las características y la función de los recursos didácticos, al igual que el uso de las tecnologías en el ámbito educativo universitario.

En cuanto a la mediación pedagógica de cursos en línea, Díaz-Barriga y Hernández (2004), Barberà (2006), Bautista et al (2008), Barberà et al (2011) y citadas por Calvo y Salas (2013), indican que se puede entender la mediación pedagógica como el proceso en el cual se facilita una serie de herramientas y estrategias didácticas mediantes las cuales se favorece un enlace entre el estudiantado y el objeto de conocimiento. Este proceso de mediación tiene como punto de partida las experiencias previas de cada estudiante, sus necesidades y características, desde las cuales se establece su zona de desarrollo real para tener claridad acerca de las áreas que se requiere fortalecer y mejorar para la optimización de su proceso de construcción de conocimientos.

Las actividades didácticas tienen una importante relación con la mediación pedagógica ya que para la mediación pedagógica es indispensable planificar previamente la acción formativa a partir del fundamento teórico y metodológico establecido desde el plan de estudios de la carrera, del diagnóstico de las características de la población a atender, de las herramientas con que cuenta la institución para la implementación de entornos virtuales de aprendizaje, así como del proceso reflexivo para orientar la construcción de conocimientos en el momento oportuno brindando la realimentación que sea necesaria (Calvo y Salas, 2013)

La mediación va más allá de que el tutor virtual tenga un dominio tecnológico de las plataformas de aprendizaje en línea: implica competencias tecno-pedagógicas que le permitan intervenir en discusiones, guiar y orientar al estudiantado en el proceso a distancia.

En un curso en línea la mediación no es sencilla: requiere capacitación y experiencia por parte del profesorado dado el cambio de paradigma que implica el uso de las plataformas de aprendizaje.

Las competencias comunicativas son parte de una adecuada mediación en cursos en línea, la redacción de mensajes e instrucciones con elementos motivacionales le permiten al tutor virtual fomentar la interacción en el curso.

\section{METODOLOGÍA}

La investigación fue de tipo cuantitativa: "este tipo de investigación ofrece la posibilidad de generalizar los resultados y brinda un punto de vista de conteo, sus características hacen posible replicar los resultados, o bien, realizar comparaciones entre estudios similares". (Ulate y Vargas, 2011) 
Entre las características que presenta dicho enfoque de investigación es que "parte de una idea, que va acotándose $y$, una vez delimitada, se derivan objetivos y preguntas de investigación, se revisa la literatura y se construye un marco o una perspectiva teórica" (Hernández, Fernández y Baptista, 2010)

Se utilizó una encuesta de investigación para recabar información del público meta. Los datos reunidos permitieron conocer los temas más importantes de comunicación y de tutoría virtual que requieren atención. Según anota Baker (1997), citado por Baray (2006) la investigación por encuesta es un método de colección de datos en los cuales se definen específicamente grupos de individuos que dan respuesta a un número de preguntas específicas.

\section{- Alcance de la investigación}

La investigación fue de tipo descriptiva, identificó características de un cierto grupo de personas; en este caso, el profesorado de un área específica y su relación con el tema de objeto de estudio.

Según Hernández, Fernández y Baptista (2010), se trata de un tipo de estudios que buscan especificar las propiedades, las características y los perfiles de personas, grupos, comunidades, procesos, objetos o cualquier otro fenómeno que se someta a un análisis.

Desde el contexto de la tutoría virtual, se recurrió a la población estudio para que identifique las principales características que predominan en la relación del tutor y estudiante.

\section{Fuentes de información}

Consistieron en su totalidad de fuentes primarias de información impresas, electrónicas y documentos internos de la institución.

Se indagaron 52 fuentes bibliográficas para garantizar la validez de la información, y encontrarlos puntos en común entre los diferentes autores acerca de: educación a distancia, tutoría virtual, comunicación, mediación, actividades dentro de cursos en línea y evaluación de los aprendizajes.

Como señala Ávila (2006) la investigación documental es una técnica que permite obtener documentos nuevos en los que es posible describir, explicar, analizar, comparar, criticar entre otras actividades intelectuales, un tema o asunto mediante el análisis de fuentes de información.

La investigación documental se centró en fuentes actualizadas, no más de cinco años de antigüedad; así mismo, de fuentes académicas procedentes de revistas científicas. Se debe destacar que se utilizan dos fuentes más antiguas que los cinco años propuestos, dada su relevancia y otra relativa a la metodología de investigación seleccionada.

Se realizó, además, la investigación bibliográfica de diversa documentación de la UNED, para extraer información del uso de los entornos virtuales, evaluación de los aprendizajes, el modelo pedagógico de la universidad y el Reglamento General Estudiantil.

\section{- Instrumentos}

Se eligió el cuestionario como instrumento para obtener los datos relevantes de la investigación. Se envió de manera electrónica a los sujetos de información, lo cual facilitó el proceso, ya que se trata de personal que no labora en planta a tiempo completo en la institución.

Se diseñaron dos encuestas para diferentes públicos meta: la primera para los tutores de los cursos en línea y la segunda para los funcionarios de planta del Área de Comunicación y Tecnología de la Dirección de Extensión Universitaria.

El diseño de las preguntas en el cuestionario se sirvió de la investigación documental realizada 
previamente acerca de los temas referentes a ta comunicación, tutoría virtual y' yatención de cursos en línea, Los cuestionarios fueron colocados en una herramienta en línea, la cual generó un vínculo de acceso. Luego el enlace fue enviado a la población de estudio vía correo electrónico; los datos brindados por los encuestados quedaron registrados en la herramienta utilizada.

\section{RESULTADOS Y COMENTARIOS}

Sólo el $17 \%$ de los tutores encuestados indican que cuentan con experiencia previa a la de la UNED en alguna otra casa de enseñanza superior facilitando cursos en línea. Solamente dos de los doce tutores respondieron afirmativamente, lo que permite inferir que la formación en el ámbito de la tutoría virtual ha ocurrido como funcionarios del Área de Comunicación y Tecnología, lo cual orienta acerca de la importancia de la formación, capacitación y asesoría que requieren los tutores para su desempeño como tutores virtuales.

En la pregunta a propósito de la frecuencia con que se revisa el entorno del curso, la mitad de los tutores externó que lo revisa diariamente. Destaca el resultado de que una tercera parte lo atiende -en conjunto- tres veces por semana y cada dos días. El dato llama la atención pues, como pauta general para los tutores virtuales del Área de Comunicación y Tecnología, está la de responder consultas en un plazo máximo de 24 horas; por consiguiente, el hecho de no revisar el curso a diario no permite cumplir con este importante requerimiento.

Con respecto al uso de los espacios de comunicación, específicamente si se utiliza el foro de consultas en los cursos, todos los tutores externan que lo utilizan como medio de comunicativo en el curso. El resultado permite comprender que se reconocen los beneficios de este tipo de medio de comunicación para el curso en línea; igualmente, se cuenta con el espacio o herramienta, pero al relacionar dicho resulta- do con el anterior, se cuenta con un medio para consultas que no se atiende a diario $y$, entonces, podrían quedar inquietudes sin resolver por más de 24 horas.

En relación con el uso de la semana introductoria para los cursos en línea, la mayoría de los tutores utilizan tal período que permite una inducción en la dinámica del curso para el estudiante. El uso de esa estrategia en los cursos en línea propicia un mejor ambientación y un conocimiento más acertado del entorno para luego iniciar las actividades evaluativas. Además, brinda noción del uso de las herramientas de la plataforma por parte del estudiante.

Como respuesta a la pregunta: ¿Al calificar actividades propuestas durante el curso (tareas, foros, blogs, wikis entre otras), las entregas realizadas por los estudiantes corresponden a lo que se solicitó en las instrucciones?, los tutores señalan que en su mayoría las entregas o participaciones por parte de los estudiantes son las que se solicitan. Entonces, es posible tener una idea de la adecuada pertinencia de las instrucciones que se redactan para las diferentes actividades de los cursos.

La pregunta realizada acerca de los elementos utilizados para la redacción de instrucciones, en la Figura 1 se puede apreciar que la mayoría de los tutores señala el uso de estos principios básicos (instrucciones generales, objetivo, valor porcentual, formato, medio de envío, fecha y hora, evaluación y ejemplos de formato y otros), tendientes a orientar al estudiantado en cuanto a la entrega de las actividades tal como se solicitan.

De la pregunta realizada acerca de los elementos utilizados para la redacción de instrucciones, en la Figura 1 se puede apreciar que la mayoría de los tutores señala el uso de estos principios básicos (instrucciones generales, objetivo, valor porcentual, formato, medio de envío, fecha y hora, evaluación y ejemplos de formato $y$ otros), tendientes a orientar al estudiantado en cuanto a la entrega de las actividades tal como se solicitan. 


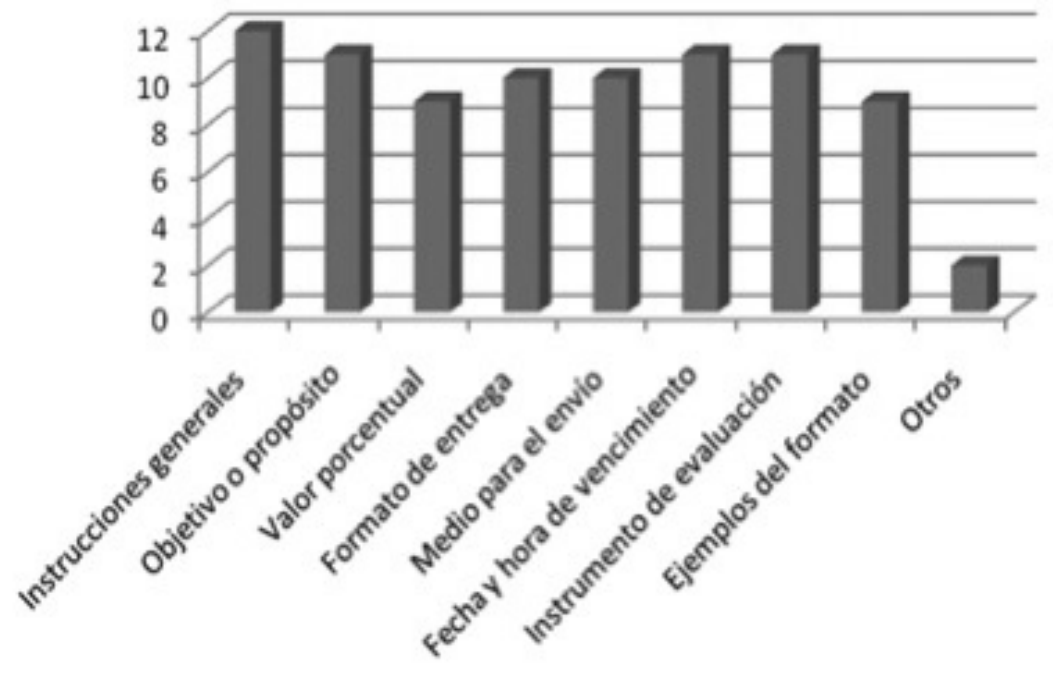

Figura 1. Uso de elementos para la redacción de instrucciones de actividades

Fuente: Francisco Mora Vicarioli (2013)

Se aportó como principio adicional el hecho de brindar los pasos para que el estudiante realice la actividad. En la Figura 1 también se aprecia cómo algunos tutores omiten algunos detalles en la redacción, principalmente: valor porcentual, formato de entrega, medio para el envío y ejemplo del formato de entrega. Este último cobra importancia pues orienta en temáticas y actividades que no son familiares para los estudiantes, por ejemplo, en mapas conceptuales, mapas mentales y ensayos, entre otros.

Tales principios fueron establecidos por la instancia asesora del PAL de la UNED, en el documento denominado Aspectos por considerar para la mediación de cursos en línea, este tipo de lineamientos también son promovidos por el CECED en su taller denominado: "Elaboración de consignas para actividades de cursos en línea". Las omisiones de esos principios en las instrucciones de las actividades pueden generar dudas en los estudiantes respecto de las entregas que deben realizar.

El resultado de la Figura 1 se puede comparar con el resultado de la consulta sobre la correspondencia entre las entregas de actividades y lo solicitado en estas, el $8 \%$ de los tutores que indicaron que las entregas algunas veces son acordes con lo solicitado. Dado que no todos los tutores utilizan todos los principios para la redacción de instrucciones. Cuando se omiten partes importantes de una instrucción, el estudiante puede confundirse y no comprender lo que se le solicita; por eso, la importancia en la precisión de las instrucciones de las actividades.

Para verificar el uso de algunos espacios o medios de comunicación de la plataforma, se realizó la pregunta siguiente: En el(los) curso(s) en línea que facilita, ¿cuál(es) herramientas para comunicar y realizar avisos a los estudiantes utiliza(correo interno, foro de consultas, anuncios, correo personal, chat y calendario)?

Como se puede apreciar en la Figura 2, la mayoría de los tutores utilizan tres de las herramientas más comunes de los entornos virtuales: correo interno, foro de consultas y anuncios. Esta última se caracteriza por informar a los estudiantes de los eventos. Los datos obtenidos reflejan que son espacios utilizados por 


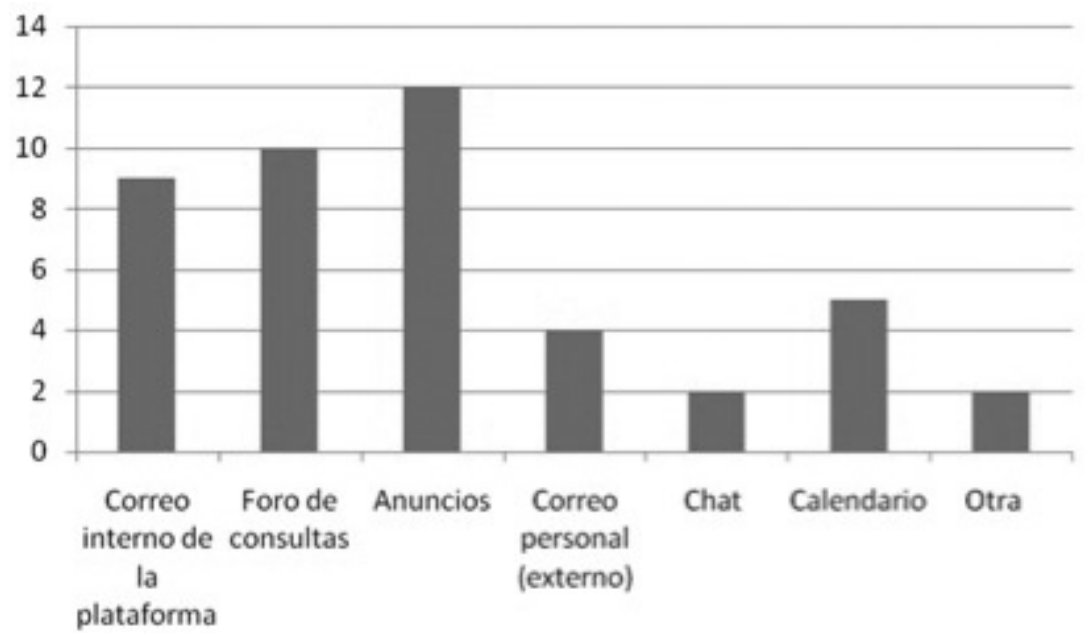

Figura 2. Uso de herramientas para comunicary realizar avisos a los estudiantes

Fuente: Francisco Mora Vicarioli (2013)

parte de los tutores, lo cual puede propiciar una comunicación e información (en el caso de los anuncios) más frecuente.

Es destacable que el correo interno cobre menos relevancia en cuanto al uso para los tutores, ya que permite hacer avisos personalizados o tratar situaciones con algunos estudiantes sin tener que involucrar al grupo entero; es más recurrente el anuncio como medio informativo.

El uso de la comunicación escrita en los cursos virtuales se entiende como toda aquella que se realiza en los distintos espacios de comunicación y realimentación de actividades tanto evaluativas como formativas. En el ítem que se consultó, $92 \%$ de los encuestados opina que es muy importante y el restante indica que es importante; las respuestas generadas dan una idea de la relevancia que se le confiereal tema. Entre las justificaciones brindadas por los tutores, son referenciadas textualmente las siguientes:

»En un entorno virtual, la comunicación tutor(a)-estudiante y estudiante-estudiante es escrita, no verbal ni gestual; por lo tanto, la escritura debe ser clara, cortés e inclusiva para evitar malas interpretaciones.

" Es una forma indispensable de comunicación; de esta depende la eficiencia y eficacia en el curso y la comunicación asertiva con el estudiante.

» Una buena comunicación escrita les ayuda a los estudiantes a entender lo que deben hacer.

Del análisis de la información anterior, los tutores reconocen la importancia de la comunicación escrita y cómo un mal uso de este medio de expresión en los cursos se puede generar confusión. También se reconoce cómo por medio de la comunicación escrita se puede promover la motivación en el estudiante; además, gracias a un buen uso de dicho recurso, se puede lograr que las instrucciones de actividades propuestas en los cursos sean comprendidas por los participantes.

Para el otro ítem de la encuesta se propuso una serie de principios para la redacción de 
los mensajes escritos, los cuales son parte del modo expositivo de la comunicación. Su finalidades la transmisión de un mensaje con la intención que se desea; a propósito de esta forma comunicativa Pazos (2010), señala los criterios que se deben vigilar: claridad (relativo a lo que se desea decir), concisión (evitar el uso de palabras que no aportan ningún contenido) y la precisión (incluir todos los datos necesarios para comprender el mensaje).

A partir de lo aportado por Pazos y al aplicar los principios del taller de Elaboración de consignas para actividades de cursos en línea impartido por el CECED, se brindaron los siguientes principios:
$»$

$»$

»

» Incorporo elementos como un saludo y una cortesía o despedida al final del mensaje.

»

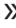

»

Reviso el tono del mensaje.

Utilizo un lenguaje sencillo y cortés.

Escribo un mensaje claro, preciso y conciso.

Utilizo un vocabulario que se adapte al receptor.

Al finalizar, reviso el mensaje para detec-
¿Qué deseo decir? tar y corregir inconsistencias o errores.

La aplicación de los principios al redactar un mensaje escrito en los cursos, el $75 \%$ de los tutores encuestados los utiliza todos, lo cual demuestra que al redactar los mensajes existen ciertos cuidados para que sean pertinentes. Se destaca que uno de los principios poco utilizados es el de revisar el tono del mensaje, relacionado con la forma de redactar el mensaje y la inclusión de detalles de cortesía, como saludo inicial y despedida; la falta de dichos elementos puede afectar la forma en que se recibe el mensaje por parte del estudiantado.

\section{CONCLUSIONES}

» La comunicación de los cursos en línea implica múltiples tareas por parte del tutor virtual, las cuales son tendentes al uso de los distintos espacios provistos para tal fin en las plataformas de aprendizaje en línea.

» La labor de la tutoría virtual es ardua por las funciones que debe asumir el profesorado en este tipo de entornos. Un rol primordial es el comunicativo y debe realizarse de manera cuidadosa.

»El tipo de comunicación que se lleva a cabo en las plataformas de aprendizaje en línea es muy variada: instrucciones, anuncios, mensajes personalizados, atención en foros de consultas, mediación de espacios y realimentación o calificación de actividades evaluativas. En cada uno, existen variadas prácticas comunicativas que favorecen la comprensión del mensaje y la manera en que el profesorado realiza sus intervenciones para dinamizar el trabajo en el curso.

El tutor en linea crea instrucciones para las actividades; las cuales son de gran relevancia, a fin de orientar la entrega que se desea por parte del estudiante. En cuanto al formato, deben cumplir ciertos principios o pasos para facilitar una mejor comprensión por parte del estudiantado.

»En la medida en que la comunicación sea apropiada, se realice con la frecuencia necesaria y se aprovechen los distintos canales de comunicación, se propicia una mejor dinámica en los procesos de aprendizaje del curso; así mismo, se propicia la armonía, la presencia y el acompañamiento que se realice, y se optimiza en general la mediación del curso. 
La comunicación en los cursos en línea debe estar acompañada de una adecuada mediación relativa al uso de principios de comunicación que permiten la armonía y una sana interacción en los cursos en línea. La mediación que se concrete en los mensajes redactados permite un mejor recibimiento por parte de los estudiantes, quienes pueden lograr dinámicas de interacción más provechosas, como las que se realizan en los foros de discusión y las wikis.

\section{BIBLIOGRAFÍA}

Angulo, C. (2013). Las herramientas digitales y el aprendizaje de contenidos. Recuperado de: http://www.ride.org. mx/docs/publicaciones/10/tecnologias_emergentes_educacion/ J24.pdf

Ávila Baray, H. (2006).Introducción a la metodología de la investigación. Recuperado de: www. eumed.net/libros/2006c/203/

Calvo, X. y Salas, N. (2013). Necesidad de unificar criterios de calidad para la mediación pedagógica de cursos en línea de la Universidad Estatal a Distancia. Recuperado de: http://web.uned.ac.cr/revistas/index.php/rps/article/view/125/pdf

Chan, M. (2010). La comunicación como mediación entre la tecnificación y la virtualización de las instituciones educativas. Recuperado de: http:// revistas.ucm.es/index.php/MESO/article/ download/MESO1010120065A/21151

Fernández, E.; Mireles, M. y Aguilar, R. (2010). La enseñanza a distancia y el rol del tutor virtual: una visión desde la sociedad del conocimiento. Recuperado de: http://www.ugr.es/ sevimeco/ revistaeticanet/numerog/Articulos/Formato/ articulo2.pdf

García, A. (coord) (2009). Concepción y tendencias de la educación a distancia en América Latina.
Recuperado de: http://www.oei.es/DOCUMENTO2caeu.pdf

Hernández, R.; Fernández, C. y Baptista, P. (2010). Metodología de la investigación. McGraw-Hill: México.

Navarro, D. y Pémberton, F. (2012). Carácter tridimensional del proceso comunicativo. Recuperado de: http://www.eumed.net/rev/cccss/19/ nlpb.pdf

Pagano, C. (2008). Los tutores en la educación a distancia: Un aporte teórico. Recuperado de: http:// www.uoc.edu/rusc/4/2/dt/esp/pagano.pdf

Pazos, E. (2010). La comunicación escrita. SECADE: San José, Costa Rica.

PAL. (2011). Aspectos por considerar para la mediación de cursos en línea. Recuperado de: http://recdidacticos.uned.ac.cr/pal/images/stories/Documentos_PAL/ManualTutoresBlackboard/aspectos_considerar_mediacion_pedagogica.pdf

PAL. (2012). Estadística 2012, Informe estadísticas de matrícula en todas las plataformas Ims: Microcampus, Webct, Blackboardlearn y Moodle. San José: UNED.

Roldán, C.; Fuentes, M.; Catalán, D.; Muñoz, M.; González, R.; Jerez, N. y Fernández, F. (2012). Comunicación no verbal en la docencia. Recuperado de: http://www.aecs.es/4_1_6.pdf

Sánchez, A.; Puerta, C. y Sánchez, L. (2010). Manual de comunicación en entornos virtuales. Recuperado de: http://www.ucn.edu.co/institucion/sala-prensa/Documents/Libro_Educacion_Virtual-_Julio_01_de_2010-_Version_Final.pdf

Santos, D. (2012). Fundamentos de la comunicación. Recuperado de: http://www.aliatuniversidades.com.mx/bibliotecasdigitales/pdf/comunicacion/Fundamentos_de_comunicacion.pdf

Ulate, I. y Vargas, E. (2011). Material complementario, marco metodológico (sección 5). Documento interno UNED. 